\title{
Antecedents of Organizational Commitment: A Review of Personal and Organizational Factors
}

\author{
Kossivi Bodjrenou${ }^{1}$, Ming Xu1 ${ }^{1}$, Kalgora Bomboma ${ }^{2}$ \\ ${ }^{1}$ Glorious Sun School of Business and Management, Donghua University, Shanghai, China \\ ${ }^{2}$ School of Economics and Management, Shanghai Maritime University, Shanghai, China \\ Email:kossbodj@gmail.com,xuming@dhu.edu.cn, research.kb@outlook.com
}

How to cite this paper: Bodjrenou, $\mathrm{K} ., \mathrm{Xu}$, M. and Bomboma, K. (2019) Antecedents of Organizational Commitment: A Review of Personal and Organizational Factors. Open Journal of Social Sciences, 7, 276-289. https://doi.org/10.4236/jss.2019.75024

Received: March 28, 2019

Accepted: May 26, 2019

Published: May 29, 2019

Copyright () 2019 by author(s) and Scientific Research Publishing Inc. This work is licensed under the Creative Commons Attribution International License (CC BY 4.0).

http://creativecommons.org/licenses/by/4.0/

(c) (i) Open Access

\begin{abstract}
Organizational commitment has been a subject of interest to scholars and human resource practitioners over many decades. However, organizations seem to struggle to have employees who will be dedicated to their organizations. In an attempt to comprehend the concept better, this paper endeavors to analyze the antecedents of organizational commitment by categorizing them so as to foster academic research in this area and help organizations in their quest to increase the commitment of their workforce. This review focused more on affective commitment over the last five years. It was found that the antecedents of organizational commitment are broad but they have been analyzed from narrow perspectives and less attention has been given to environmental or external factors. It suggested a more classification of the antecedents of organizational commitment. Practical implications and future research directions were suggested.
\end{abstract}

\section{Keywords}

Organizational Commitment, Organizational Characteristics, Individual Factors

\section{Introduction}

Organizational Commitment which is not a recent concept drew the attention of many scholars and practitioners and as such many scholars attempted to define the term "Organizational Commitment". Organizational Commitment (OC) was defined as the extent to which an employee is attached to the organization [1]. It was also described as "the process by which individuals become locked into a certain organization" [2]. The concept was also viewed as the extent to which employees are involved in and identify themselves to their organization [3]. 
Another group of researchers defined organizational commitment as an emotional response expressed by employee's behaviors, beliefs, and attitudes [4]. It is a psychological state that expresses the degree of affiliation of an employee to an organization. Earlier research works on the subject has been consolidated in the Three Component Model (TCM) which identified three types of organizational commitment: affective, continuous and normative commitments [5]. Affective Commitment is the emotional attachment of the employee to an organization. Normative Commitment is related to the personal ethic, moral or ideology. Continuance commitment is linked with the costs associated with quitting one's job.

More recently OC has been defined as the desire of an employee to be part of an organization and to contribute to the achievement of the objectives of that entity [6]. A group of scholars argued that OC is an individual's attachment to an organization with which he or she is willing to continue working for different reasons [7].

Another group described OC as a chief determinant in the rapport that an employee has with his/her employer [8]. OC was also associated to the deepness or shallowness of the attachment of an employee to his/her organization, the satisfaction derived in working for such an entity and the willingness to continue being a member of it [9]. All the descriptions of OC given above by various scholars have in common the tie between the organization and the employee. A strong relation between an employee and an employer implies a high probability to maintain the employment contract that binds these parties. Though organizations are aware of the fact that a high commitment reduces employee turnover many companies seem to keep their workforce for a long period of time. This led may make one inquisitive to better to understand the factors that influence organizational commitment. This paper aims to comprehend the concept of organizational commitment by analyzing some of its determinant factors and categorizing them as to foster academic research in this area and help organizations in their quest to increase the commitment of their employees. As OC is a relationship between an individual and the organization he or she works for, to achieve the objective of the study the antecedents of OC will be viewed first from organization perspective then from personal angle.

\section{Organization Internal Factors}

\subsection{Training and Development}

As far as employee training and development is concerned, a positive correlation between employee development initiative and organizational commitment has been observed [10]. It was found that employee's training affects positively organizational commitment and it ultimately reduces turnover and turnover intentions [11]. The results of the investigation of [12] on the subject, indicated that training and development contribute to build employee's organizational commitment. Training and development has been looked at from the perspective of 
developmental support offered to employees and it was found that they have a favorable effect on affective organizational commitment and turnover intentions [13].

Other scholars found that association of other factors that increases organization. In that line it has been argued that the provision of leadership and coaching training and development to supervisors, the availability of resources are significant predictors of organizational commitment, generally speaking and affective commitment more specifically [14]. In the Asian context of South Korea, it was observed that the association between motivation for training or development and Organization-Related Variables significantly predicts organizational commitment [15].

It was observed that employees' affective commitment to their organization is strong in a context of mutual investment in employment relationship [16]. The investment on the part of the organization can be in the form of employee training and development. When employees perceived that they are invested in through training and development they reciprocate by being more committed to their organization. This observation is made on the norm of reciprocity. Relationships play an important role in building high affective commitment. They also found that employees with high normative commitment are reported to have stronger work unit relations.

\subsection{Leadership}

As far as the relationship between organizational commitment and leadership is concerned, it has been observed that leadership behavior is a significant predictor of affective organizational commitment and this ultimately reduces the withdrawal behavior of lateness [13]. In the same respect it was found that transformational leadership increases employee's organizational commitment [17]. Transformational leadership behavior of direct supervisors is found to be a significant contributor to organizational commitment and affective commitment especially in the context of change management or the implementation of change [18]. In the same line, it has been argued that transformational leadership best practices and teachers' commitment to organization have a significant positive association [19]. Transformational leadership was a significant factor related to teachers' commitment to an organization and even to the commitment of the teaching profession. A research team studied leadership-organization commitment relationship and found that good leadership practices positively correlate with organizational commitment [15]. Another team supported the view that best leadership practices increase organizational commitment [20]. In the same line, as leadership is about vision and objective setting, they also found that clarity of vision helps increase employee commitment to an organization's objectives [20]. Leadership behaviors through the empowering process contribute to increase OC in Asian settings such South Korea [15].

A lot of work has been done in the West on organizational commitment but 
the subject is less studied in the other parts of the world. Leadership best practice has generally been associated with organizational commitment. However, existing studies have not been the kind of leadership style that best predict organization commitment.

Organization commitment is an organizational outcome but the analysis of the association of leadership and this concept has been carried out on individual leadership basis instead of organizational leadership. Many practitioners observed that leadership culture is related positively to employee retention but scholars have given no or little attention to the relationship between leadership culture and employees' commitment to their organization.

\subsection{Mentoring}

Having a mentor has been significantly and positively associated with affective organizational commitment [21]. Still about the association between mentorship and organization commitment, it found that having a mentor inside the organization significantly and positively impacts affective organizational commitment more than having a mentor outside the organization [21]. It was reported that "The psychosocial support of having a friend, role model, and counselor increases protégés sense of self-worth and competence" [22]. It was also observed that leadership in the form of effective mentoring through "job-related coaching and assistance in overcoming career challenges" increases organizational commitment [22]. Organizational commitment has been analyzed on the basis of mentor-mentoree relationship and comparing salespeople with and without mentors, and mentees with mentors, it was observed that having a mentor is significantly and positively associated with affective organizational commitment and affective occupational commitment [21].

\subsection{Job Autonomy}

Leadership can be viewed from the perspective of job autonomy. Autonomy is related to the degree of freedom on job. It depends and results from trust of the supervisor and this can be linked to leadership. Autonomy has been defined as "the ability to choose how to do one's work, having influence over one's work, and flexibility in workload decisions" [23]. Autonomy is found to significantly and positively influence organizational commitment [12] [24]. Leadership empowerment in the form of autonomy on the job has a favorable effect on affective organizational commitment and turnover intentions [13]. A study of the relationship between autonomy and organizational commitment revealed that the degree of autonomy given on the job is a strong predictor of organizational commitment [24]. The provision of training and development to employees may result in a supervisor having more trust in the subordinate and granting him or her autonomy on the job.

\subsection{Organizational Support}

The association of organizational support and organizational commitment has 
been examined from global and from specific perspectives.

From a global perspective, it was found that organizational support is a significant influencer of organizational commitment [25] [26]. It was observed that organizational support positively and significantly influences an employee commitment to an organization and it was found that the way an employee perceives the support provided by an organization influences his or her commitment towards that employer [12]. This perception influences more specifically affective commitment [12]. Analyzing affective commitment from a social exchange standpoint, it was observed that affective organizational commitment is strongly associated with social exchange relationships [27]. Organization support through social exchange is needed to increase affective commitment [16]. In the same line it was observed that "employees do not perform their tasks in a vacuum and that the social exchange relationship matters for affective commitment" [28]. It was found that organizational support in the form of a relationship-oriented HR system contributes to employees' collective organizational commitment [29]. The results of the study of another research team indicated that perceived quality of care is strong predictors of organizational commitment [24]. The way employees feel they are valued or being taking care of is a significant influencer of organizational commitment. Organizational climate has been associated with organizational commitment as well. Organizational climate (which is an integral part of overall organization of hospitals, referring to correct social behavior and the way to manage conflicts, ambiguities, and challenges in hospital organizations) is a predictor of organizational commitment [30]. It was found that employees' perceived ethical work climate positively and significantly correlates with organizational outcomes [31]. Employees' affective commitment to their organization is strong in a context of mutual investment in an employment relationship [16]. The relationship between organizational support and organizational commitment was analyzed through the lens of psychological contract, emotional exhaustion and affective commitment to supervisors it was found that affective organizational commitment and psychological contract breach have a significant negative association [32].

The association of organizational support and organizational commitment has been examined from specific perspectives such as coworkers support and relationship with direct supervisor.

Examining organizational commitment from the perspective of the commitment of the employee to his or her direct supervisor, it was found that affective organizational commitment relates to affective commitment to a supervisor [32]. The relationship between the employee and the supervisor was analyzed through the lens of their compatibility and it was observed that perceived person-supervisor (P-S) fit significantly influences affective organizational commitment [33]. It was argued that supervisor support increases employee's organizational commitment [17]. It was found that supervisor-subordinate relationship affects organizational commitment [34]. It was argued that organizational support in the form of support 
from the supervisor positively associates generally with affective commitment [14]. Based on affective events theory (AET), it has been observed that the affective commitment of a subordinate who has experienced abuse from a supervisor is likely to decrease and this employee may in turn leave the organization [34]. A group of scholars found that effective direct supervision contribute to increase an employee's commitment to an organization, more specifically his or her affective commitment [18]. Another group of scholars analyzed the relationship between organizational support and organizational commitment through the lens of psychological contract, emotional exhaustion and affective commitment to supervisor and observed that affective organizational commitment relates to affective commitment to a supervisor [32]. Support from a supervisor has a social aspect and a professional aspect. Some social support theorists found that the element of social support plays an important role in the pursuit to increase employees' commitment to their employers [35]. Previous studies have been less specific about the extent to which each aspect influences organizational commitment.

Similarly, coworkers' support has also been associated with organizational support. In that regard it has been argued that organizational support in the form of the support from coworkers were positively associated generally with organizational commitment and more specifically with affective commitment [14]. Supervisors and co-workers or colleagues support reflects organizational support, which is a strong influencer of organizational commitment [24].

Coworkers' support can either be social or professional or even both. Current literature gave attention to the specific incidence of social and the professional dimensions of coworkers' support on organization commitment but not social support outside the organization.

Organizational support can be offered from three sources: co-workers, supervisors, and management. Current literature has devoted less attention to the specific ways in which management support could affect organizational commitment.

\section{Organization Life and Personal Life}

Social support in the context of family life has been cited among one of the most significant influencers of organizational commitment. Work-family conflict has negative effects on employee's commitment [36]. Good work-life balance ensures a high employee commitment especially on project works. It was reported that WLC (Work-Life-Conflict) negatively relates to organizational commitment in both Western and Asian contexts and reduced WLC or good WLB (Work-Life-Balance) has a positive impact on organizational commitment [22]. In line with social support theory, it was found that family-supportive organizational perceptions (FSOP) associate with employee affective commitment and it was argued that employee's work-to-family conflict relates to employee's commitment to a firm and work-to-family enrichment positively relates to em- 
ployee affective commitment [35].

It has generally been observed that family-supportive organizational perceptions (FSOP) positively associate with organizational commitment. However, the life of an individual has many aspects (such as health, marriage, children ...) and no specific dimensions of an employee's life have been associated with organizational commitment.

\section{Individual Factors and Organization Characteristics}

Organizational commitment has not only been associated with single factors but also with groups of factors such as individual-related and organization-related characteristics. As far as individual-related factors are concerned, it was observed individual characteristics or individual-level or individual-related variables explain differences in employee's commitment to their organization [24]. It has also been observed that employee's gender is associated with organizational commitment [35]. Concerning educational level, while some researchers found that the lower the educational level the higher the level of commitment [37] others observed that qualification negatively correlates to organization commitment [38] [39]. Educational level, job position, job description, and current organizational tenure are strong predictors of employee's commitment to their organization [40]. It was found educational level negatively correlates with employee commitment [41]. It has been reported that: "married women were more committed to their organization than single women because of married workers' responsibilities to provide financial support for their family" [22]. Marital status is associated with organizational commitment and it has been observed that parental status is associated with organizational commitment and it was also found that single-versus dual-earner couple status is associated with organizational commitment [35].

Conducting a comparative analysis in an Asian and a Western context, namely Japan and the US, it was observed that the nationality of employees influence their commitment towards their organization and it was reported that "The association between perceived $P$-S fit and affective organizational commitment was stronger in Japan than in the US, whereas the strength of the link between perceived $P$-O fit and affective organizational commitment did not differ across the two countries" [33]. A team observed that employee's personality influences an employee's commitment to an organization [42]. The same team examined employee organizational commitment based on the five-factor model of personality traits and social exchange theory in the Asian context of South Korea and found that some personality traits such as Agreeableness, Conscientiousness, and Emotional Stability significantly associates with organizational commitment. Several studies detected a relation between affective commitment and tenure and some cases specifically related it to job tenure [38] [43] [44]. At the individual level, job tenure significantly relates to affective commitment [16]. A potential explanation found is in the fact that long service in a particular organi- 
zation leads to the knowledge of the operations of the organization, an increased sense of self-esteem and the technical know-how that gives the feeling of adding value to the organization [45]. Other studies with the same purpose discovered that responsibilities or position is not a significant influential factor of organization commitment [46].

Affective commitment has also been associated with organization-level factors. It was observed that the labor force in the manufacturing sector is more committed than the employees in the service sector [47]. Organizational characteristics or organization-level or organization-related variables explain differences in employee's commitment to their organization [24]. The organizational characteristics-organizational commitment relation was analyzed through the lens of the compatibility of the employee and the organization and it was found that "Perceived P-S fit and affective organizational commitment are found to be related both directly and indirectly (through perceived $P$-O fit) in Japan but only indirectly in the US" it was observed that in Japan and the US "perceived $P$-O fit positively translates into affective organizational commitment through collectivistic values" [33].

Individual-level factors explain differences in employee's commitment to their organization more than organization-related variables [24].

\section{Other Antecedents}

The antecedents mentioned above are not the ones related to organizational commitment. Many other antecedents have been associated with organizational commitment. It was found that a positive impact of income changes on $\mathrm{AC}$ changes and observed that "higher levels of income lead to higher levels of affective commitment" [48]. Reward for effort contributes to increase the commitment of an employee to his/her organization [17]. Remuneration above competitors contributes to build a strong employee's organizational commitment and job insecurity negatively correlates with organizational commitment in general and affective commitment in particular [12]. Job involvement increases organizational commitment [30]. A research team conducted a study with the aim to examine the factors that influence the degree of commitment of employees in the hotel industry and found that job stress and organizational commitment negatively associate [49]. It was also observed that the adoption of the Employee Performance Management (EPM) and the consistency in its implementation increase organizational commitment, particularly affective commitment and in turn reduces employee turnover [50].

\section{Categorization Personal and Organizational Factors}

It has been identified factors that can influence affective commitment and classified them into two categories [51]. The first category is related to individual elements such as age, personality, education or values orientation. The second category is organizational and has to do with issues such as job description and 
management support. The review of literature above also analyzed factors influencing organizational commitment particularly affective commitment from organizational and personal perspectives but attempted to deepen the grouping. Organizational factors can be divided into two main groups: managerial factors and situational factors. Managerial factors are related to management issues such as leadership development, autonomy on the job, and organizational support. Situational factors are related to the situation of the organization such as its size, the industry in which it operates, and its image. Personal factors pertain to a specific employee or group of employees. They are related to his or her demographics such as age, gender, educational level, experience, and marital status. However, some organizational and personal factors are neither related exclusively to the organization or the individual. These factors could be classified as job related factors. These are job or organizational tenure, position. This review focuses only on organizational factors and personal factors but it is worth noting that organizational commitment is also affected by external factors such as the economy, the culture, and regulations.

\section{Practical Implications}

The antecedents of organizational commitment are broad but they have been analyzed from narrow perspectives and less attention has been given to environmental or external factors. An attempt to increase organizational commitment by working on only some individual factors or a group of factors alone will bring forth little result. Organizations should rather take into consideration all the factors. Inclusion of external factors such as the economy, the culture that cannot be controlled by an organization can help save resources because the same amount of effort might not be needed in situations where external factors predominantly influence organizational commitment. Organizations should adopt an individualistic approach by grouping them by similar features, in addition to a global approach. The global approach assumes that there is a general way to increase the commitment level of all employees towards their organization. However, employees are not the same because their circumstance, personality, preferences and situation are different. Employers should also take into consideration talents or valuable employees capable of adding value to their organization. More attentive care should be given to such employees so as to retain them and avoid the waste of resources on employees who are less likely to contribute significantly to the achievement of the objectives of their organization.

\section{Future Research Directions and Limitations}

A lot of work has been done in the West on organizational commitment but the subject is less studied in the other parts of the world. Future studies can seek to identify the factors that influence organizational commitment in other parts of the world and develop models that are more suitable to their circumstances.

Employee commitment is an organizational outcome but the analysis of the 
association of leadership and this concept has been carried out on individual leadership basis instead of organizational leadership. Many practitioners observed that leadership culture is related positively to employee retention but scholars have given no or little attention to the relationship between leadership culture and employees' commitment to their organization. In the future, scholars could seek to establish the relationship between organizational commitment and leadership culture. Leadership best practice has generally been associated with organizational commitment. However, existing studies have not been the kind of leadership style that best predict organization commitment. Future studies can seek to identify the kind of leadership style that best predicts organization commitment.

Support from a supervisor has a social aspect and a professional aspect. Social support theorists observed that the element of social support plays an important role in the quest to increase employees' commitment to their employers [35]. For instance, it has generally been observed that family-supportive organizational perceptions (FSOP) positively associate with organizational commitment. However, the social life of an individual has many other aspects such as health, income management, parenting and so on and these areas have not been associated with organizational commitment. Future studies could seek to analyze the association between the areas of an employee's and organizational commitment so as to better comprehend the concept.

Coworkers' support can either be social or professional or even both. Current literature gives attention to the specific incidence of social and professional dimensions of coworkers' support on organization commitment. Organizational support can be offered from three sources: co-workers, supervisors, and management. Current literature has devoted less attention to the specific ways in which management support could affect organizational commitment. Future studies could investigate specific ways in which co-workers, supervisors and management influences organizational support.

Though the objective of this study is to provide a better understanding of organization commitment by categorizing organizational and personal factors susceptible to affect the degree of attachment of workforce to the employer, this research did not cover external or environmental issues that are equally important.

\section{Conclusion}

The antecedents of organizational commitment are broad. However, they have been examined from narrow perspectives such as single individual factors or isolated organizational features. Little attention or consideration has been given to external factors such as the economy, the socio-political situation, and the competitive environment. To effectively increase employees' commitment to an organization, they will need to take into consideration the personal and organizational factors, and environmental dynamics that are neither personal nor or- 
ganizational. In addition, they should adopt a dual approach: global approach to address common concerns of their workforce and also the individualistic approach to increase the commitment of talents that they cannot afford to lose.

\section{Conflicts of Interest}

The authors declare no conflicts of interest regarding the publication of this paper.

\section{References}

[1] Porter, L., Steers, R., Mowday, R. and Boulian, P. (1974) Organizational Commitment, Job Satisfaction and Turnover among Psychiatric Technicians. Journal of Applied Psychology, 59, 603-609. https://doi.org/10.1037/h0037335

[2] Mowday, R.T., Porter, L.M. and Steers, R.M. (1982) Employee-Organization Linkages: The Psychology of Commitment, Absenteeism, and Turnover. Academic Press, New York.

[3] O’Reilly, C.A. and Chatman, J. (1986) Organizational Commitment and Psychological Attachment: The Effects of Compliance, Identification, and Internalization on Prosocial Behavior. Journal of Applied Psychology, 71, 492-499. https://doi.org/10.1037/0021-9010.71.3.492

[4] Meyer, J.P. and Allen, N.J. (1997) Commitment in the Workplace: Theory, Research, and Application. 2nd Edition, Sage, Thousand Oaks.

[5] Meyer, J. and Allen, N. (1991) A Three-Component Conceptualization of Organizational Commitment. Human Resources Management Review, 1, 81-89. https://doi.org/10.1016/1053-4822(91)90011-Z

[6] Sani, A. (2013) Role of Procedural Justice, Organizational Commitment and Job Satisfaction on Job Performance: The Mediating Effects of Organizational Citizenship Behavior. International Journal of Business and Management, 8, 57-67. https://doi.org/10.5539/ijbm.v8n15p57

[7] Ellenbecker, C.H. and Custman, M. (2012) Home Healthcare Nurse Retention and Patient Outcome Model: Discussion and Model Development. Journal of Advanced Nursing, 68, 1881-1893. https://doi.org/10.1111/j.1365-2648.2011.05889.x

[8] Rehman, S., Shareef, A., Mahmood, A. and Ishaque, A. (2012) Perceived Leadership Styles and Organizational Commitment. Interdisciplinary Journal of Contemporary Research in Business, 4, 616-626.

[9] Dey, T. (2012) Predictors of Organizational Commitment and Union Commitment: A Conceptual Study. IUP Journal of Organizational Behavior, 11, 62-75.

[10] Jehanzeb, K. and Mohanty, J. (2018) Impact of Employee Development on Job Satisfaction and Organizational Commitment: Person-Organization Fit as Moderator. International Journal of Training and Development, 22, 171-191. https://doi.org/10.1111/ijtd.12127

[11] Jehanzeb, K., Rasheed, A. and Rasheed, M.F. (2013) Organizational Commitment and Turnover Intentions: Impact of Employee's Training in Private Sector of Saudi Arabia. International Journal of Business and Management, 8, 79-90. https://doi.org/10.5539/ijbm.v8n8p79

[12] Tian, Q., Zhang, L. and Zou, W. (2014) Job Insecurity and Counterproductive Behavior of Casino Dealers-The Mediating Role of Affective Commitment and Moderating Role of Supervisor Support. International Journal of Hospitality Man- 
agement, 40, 29-36. https://doi.org/10.1016/j.ijhm.2014.03.005

[13] Kim, M. and Beehr, T.A. (2018) Empowering Leadership: Leading People to Be Present through Affective Organizational Commitment? The International Journal of Human Resource Management, 1-25. https://doi.org/10.1080/09585192.2018.1424017

[14] Orgambídez, A. and Almeida, H. (2018) Predictors of Organizational Commitment in Nursing: Results from Portugal. Investigacion Y Educacion En Enfermeria, 36, 1-9. https://doi.org/10.17533/udea.iee.v36n1e14

[15] Kim, S. and Shin, M. (2017) Transformational Leadership Behaviors, the Empowering Process, and Organizational Commitment: Investigating the Moderating Role of Organizational Structure in Korea. International Journal of Human Resource Management, 30, 251-275. https://doi.org/10.1080/09585192.2016.1278253

[16] Audenaert, M., George, B. and Decramer, A. (2017) How a Demanding Employment Relationship Relates to Affective Commitment in Public Organizations: A Multilevel Analysis. Public Administration, 97, 11-27.

https://doi.org/10.1111/padm.12378

[17] Vele, C.L. (2018) Organizational Leadership Designed at Ensuring Employee Commitment. Proceedings of the 7 th International RAIS Conference on Social Sciences, Tampa, 19-20 February 2018, 97-105. https://doi.org/10.2139/ssrn.3152103

[18] Voet, J.V.D., Kuipers, B.S. and Groeneveld, S. (2017) Implementing Change in Public Organizations: The Relationship between Leadership and Affective Commitment to Change in a Public Sector Context. Public Management Review, 18, 842-865.

[19] Ibrahim, M.S., Ghavifekr, S., Ling, S., Siraj, S. and Azeez, M.I.K. (2014) Can Transformational Leadership Influence on Teachers' Commitment towards Organization, Teaching Profession, and Students Learning? A Quantitative Analysis. Asia Pacific Education Review, 15, 177-190. https://doi.org/10.1007/s12564-013-9308-3

[20] Wei, F., Lee, J. and Kwan, H.K. (2016) Impact of Active Constructive Leadership and Passive Corrective Leadership on Collective Organizational Commitment. Leadership and Organization Development Journal, 37, 822-842. https://doi.org/10.1108/LODJ-08-2014-0150

[21] Hartmann, N.N., Rutherford, B.N., Hamwi, G.A. and Friend, S.B. (2013) The Effects of Mentoring on Salesperson Commitment. Journal of Business Research, 66, 2294-2300. https://doi.org/10.1016/j.jbusres.2012.03.001

[22] Kim, H.K. and Kim, Y.H. (2017) Work-Life Conflict of Married and Childless Single Female Workers. International Journal of Manpower, 38, 1157-1170. https://doi.org/10.1108/IJM-06-2015-0089

[23] Christeen, G. (2015) Retaining Professional Workers: What Makes Them Stay? Employee Relations, 37, 102-121. https://doi.org/10.1108/ER-10-2013-0151

[24] Miedaner, F., Kuntz, L., Enke, C., Roth, B. and Nitzsche, A. (2018) Exploring the Differential Impact of Individual and Organizational Factors on Organizational Commitment of Physicians and Nurses. BMC Health Services Research, 18, 180. https://doi.org/10.1186/s12913-018-2977-1

[25] Butts, M.M., Casper, W.J. and Yang, T.S. (2013) How Important Are Work-Family Support Policies? A Meta-Analytic Investigation of Their Effects on Employee Outcomes. Journal of Applied Psychology, 98, 1-25. https://doi.org/10.1037/a0030389

[26] Odle-Dusseau, H.N., Britt, T.W. and Greene-Shortridge, T.M. (2012) Organizational Work-Family Resources as Predictors of Job Performance and Attitudes: The Process of Work-Family Conflict and Enrichment. Journal of Occupational Health Psychology, 17, 28-40. https://doi.org/10.1037/a0026428 
[27] Buch, R. (2015) Leader-Member Exchange as a Moderator of the Relationship between Employee-Organization Exchange and Affective Commitment. International Journal of Human Resource Management, 26, 59-79. https://doi.org/10.1080/09585192.2014.934897

[28] Caillier, J.G. (2017) The Impact of High-Quality Workplace Relationships in Public Organizations. Public Administration, 95, 638-653. https://doi.org/10.1111/padm.12328

[29] Kehoe, R.R. and Collins, C.J. (2017) Human Resource Management and Unit Performance in Knowledge-Intensive Work. Journal of Applied Psychology, 102, 1222-1236. https://doi.org/10.1037/apl0000216

[30] Kalhor, R., Khosravizadeh, O., Moosavi, S., Heidari, M. and Habibi, H. (2018) Role of Organizational Climate in Job Involvement: A Way to Develop the Organizational Commitment of Nursing Staff. Journal of Evidence-Based Integrative Medicine, 23, 1-5. https://doi.org/10.1177/2515690X18790726

[31] Abou, E.H. (2017) Relationship between Ethical Work Climate and Nurses' Perception of Organizational Support, Commitment, Job Satisfaction and Turnover Intent. Nursing Ethics, 24, 151-166. https://doi.org/10.1177/0969733015594667

[32] Lapointe, E., Vandenberghe, C. and Boudrias, J.S. (2013) Psychological Contract Breach, Affective Commitment to Organization and Supervisor, and Newcomer Adjustment: A Three-Wave Moderated Mediation Model. Journal of Vocational Behavior, 83, 528-538. https://doi.org/10.1016/j.jvb.2013.07.008

[33] Astakhova, M.N. (2016) Explaining the Effects of Perceived Person-Supervisor Fit and Person-Organization Fit on Organizational Commitment in the U.S. and Japan. Journal of Business Research, 69, 956-963. https://doi.org/10.1016/j.jbusres.2015.08.039

[34] Tillman, C.J., Gonzalez, K., Crawford, W.S. and Lawrence, E.R. (2018) Affective Responses to Abuse in the Workplace: The Role of Hope and Affective Commitment. International Journal of Selection and Assessment, 26, 57-65. https://doi.org/10.1111/ijsa.12203

[35] Wayne, J.H., Casper, W.J., Matthews, R.A. and Allen, T.D. (2013) Family-Supportive Organization Perceptions and Organizational Commitment: The Mediating Role of Work-Family Conflict and Enrichment and Partner Attitudes. Journal of Applied Psychology, 98, 606-622. https://doi.org/10.1037/a0032491

[36] Zheng, J. and Wu, G. (2018) Work-Family Conflict, Perceived Organizational Support and Professional Commitment: A Mediation Mechanism for Chinese Project Professionals. International Journal of Environmental Research and Public Health, 15, 344. https://doi.org/10.3390/ijerph15020344

[37] Amangala, T.A. (2013) The Effects of Demographic Characteristics on Organizational Commitment: A Study of Salespersons in the Soft Drink Industry in Nigeria. European Journal of Business and Management, 5, 109-118.

[38] Igbal, A. (2011) The Impact Assessment of Demographic Factors on Faculty Commitment in the Kingdom of Saudi Arabia Universities. Journal of College Teaching and Learning, 8, 1-13. https://doi.org/10.19030/tlc.v8i2.3552

[39] Al-Kahtani, S.N. (2012) An Exploratory Study of Organizational Commitment, Demographic Variables and Job and Work Related Variables among Employees in Kingdom of Saudi Arabia. Online International Interdisciplinary Research Journal, 3, $1-13$.

[40] Timalsina, R., Sarala, K.C., Rai, N. and Chhantyal, A. (2018) Predictors of Organizational Commitment among University Nursing Faculty of Kathmandu Valley, 
Nepal. BMC Nursing, 17, 30. https://doi.org/10.1186/s12912-018-0298-7

[41] Savič, S.B. and Robida, A. (2013) Capacity of Middle Management in Health-Care Organizations for Working with People-The Case of Slovenian Hospitals. Human Resources for Health, 11, 18. https://doi.org/10.1186/1478-4491-11-18

[42] Guay, R.P., Choi, D., Oh, I.S., Mitchell, M.S., Mount, M.K. and Shin, K.H. (2016) Why People Harm the Organization and Its Members: Relationships among Personality, Organizational Commitment, and Workplace Deviance. Human Performance, 29, 1-15. https://doi.org/10.1080/08959285.2015.1120305

[43] Salami, S.O. (2008) Demographic and Psychological Factors Predicting Organizational Commitment among Industrial Workers. Anthropologist, 10, 31-38. https://doi.org/10.1080/09720073.2008.11891026

[44] Azeem, S.M. (2010) Personality Hardiness, Job Involvement and Job Burnout among Teachers. International Journal of Vocational and Technical Education, 2, 36-40.

[45] Affum-Osei, E., Acquaah, E. and Acheampong, P. (2015) Relationship between Organizational Commitment and Demographic Variables: Evidence from a Commercial Bank in Ghana. American Journal of Industrial and Business Management, 5, 769-778. https://doi.org/10.4236/ajibm.2015.512074

[46] Kumasey, S.A., Delle, E. and Ofei, B.S. (2014) Occupational Stress and Organizational Commitment: Does Sex and Managerial Status Matter? International Journal of Business and Social Research, 4, 173-182.

[47] Konya, V., Matic, D. and Pavlovic, J. (2016) The Influence of Demographics, Job Characteristics and Characteristics of Organizations on Employee Commitment. Acta Polytechnica Hungarica, 14, 119-138.

[48] Gao-Urhahn, X., Biemann, T. and Jaros, S.J. (2016) How Affective Commitment to the Organization Changes over Time: A Longitudinal Analysis of the Reciprocal Relationships between Affective Organizational Commitment and Income. Journal of Organizational Behavior, 91, 1106-1115.

[49] Garg, S. and Dhar, R.L. (2014) Effects of Stress, LMX and Perceived Organizational Support on Service Quality: Mediating Effects of Organizational Commitment. Journal of Hospitality and Tourism Management, 21, 64-75. https://doi.org/10.1016/j.jhtm.2014.07.002

[50] Waeyenberg, T.V., Decramer, A., Desmidt, S. and Audenaert, M. (2017) The Relationship between Employee Performance Management and Civil Servants' Turnover Intentions: A Test of the Mediating Roles of System Satisfaction and Affective Commitment. Public Management Review, 19, 747-764. https://doi.org/10.1080/14719037.2016.1209230

[51] Kate, W. and Masako, T. (2002) Reframing Organizational Commitment within a Contemporary Careers Framework. Cornell University, Ithaca. 